\title{
UNUSUAL PRESENTATIONS OF LEUKAEMIAS- A REVIEW OF TWO CASES
}

Seena A. $R^{1}$, Lilarani Vijayaraghavan ${ }^{2}$

${ }^{1}$ Associate Professor, Department of Pathology, Medical College, Alappuzha.

${ }^{2}$ Professor, Department of Pathology, Medical College, Alappuzha.

HOW TO CITE THIS ARTICLE: Seena AR, Vijayaraghavan L. Unusual presentations of leukaemias- A review of two cases. J. Evolution Med. Dent. Sci. 2017;6(49):3810-3812, DOI: $10.14260 / J e m d s / 2017 / 823$

\section{PRESENTATION OF CASES}

Leukaemias are haematological malignancies with a wide variety of symptoms. Most cases are diagnosed from blood and bone marrow picture, supported by clinical findings, and confirmed by further investigations. However, some cases present with unusual symptoms leading to difficulty in diagnosis and warranting a more vigilant investigation. Here are two such cases.

\section{Case 1}

A 76-year-old man presented with a perianal ulcer and chronic obstructive pulmonary disease. He was treated locally but the ulcer did not respond. No organomegaly or lymphadenopathy was detected. His total count was 700 per cu.mm of which more than $90 \%$ were lymphocytes (Figure 1). No abnormal cells were seen. Imprint smear from the ulcer showed mainly necrosis and few cells with high nucleocytoplasmic ratio. Further details were obscured by necrotic debris. Repeat peripheral smear showed the same cells (Figure 2). The nuclei showed fine chromatin and 2-3 nucleoli. Bone marrow, also showed similar cells which stained with myeloperoxidase (Figure 3). Hence, the diagnosis given was AML-M2 (with maturation). Aspiration cytology from the ulcer was suggested to confirm soft tissue infiltration which is occasionally seen in this type of leukaemia, but the patient developed cor pulmonale and died of cardiorespiratory arrest.

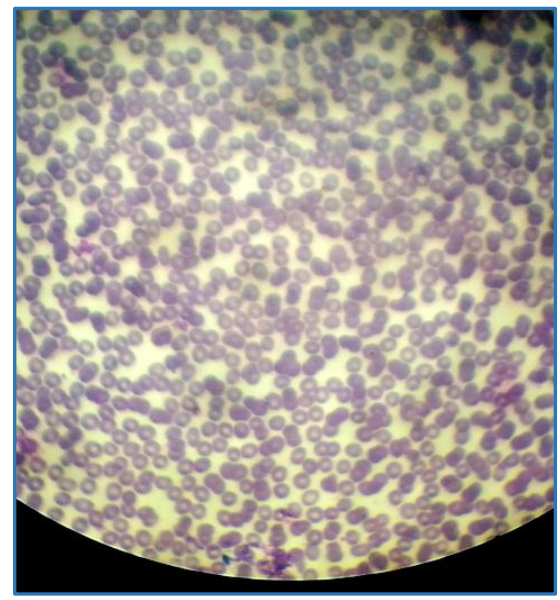

Figure 1. Peripheral Smear showing Marked Leucopenia

Financial or Other, Competing Interest: None.

Submission 01-05-2017, Peer Review 06-06-2017,

Acceptance 12-06-2017, Published 19-06-2017.

Corresponding Author:

Dr. Seena A. R,

Manusmrithi, TC 68/2352,

NKRA-12, Manacaud P.O

Thiruvananthapuram-695009.

E-mail: seenaar@yahoo.com

DOI: $10.14260 /$ jemds/2017/823

\section{(c) (i) $(9)$}

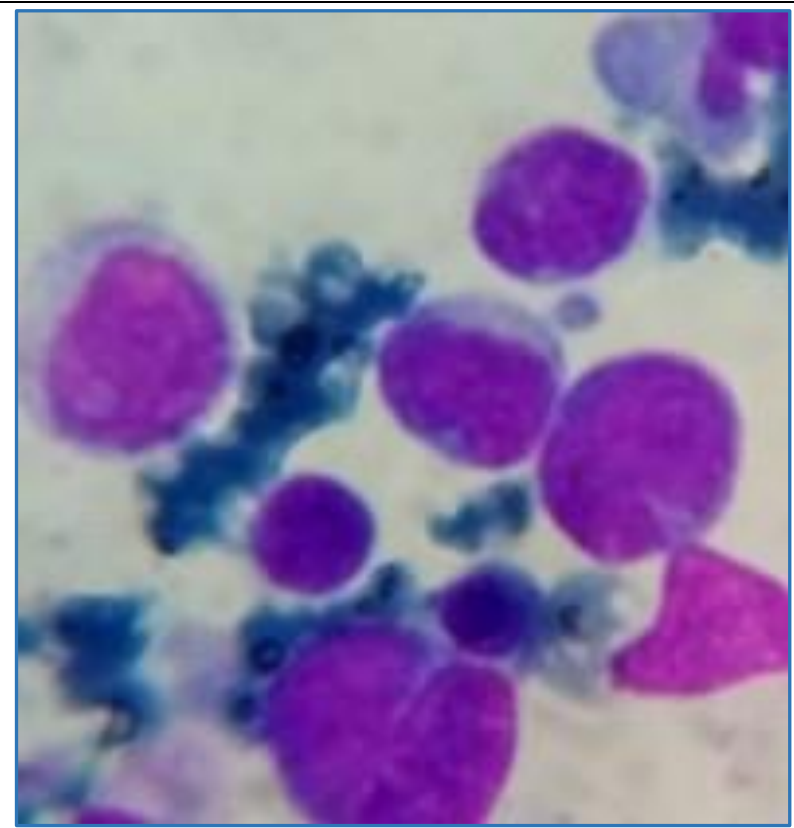

Figure 2. Atypical Cells in Repeat Peripheral Smear. The Cells show 2-3 Nucleoli

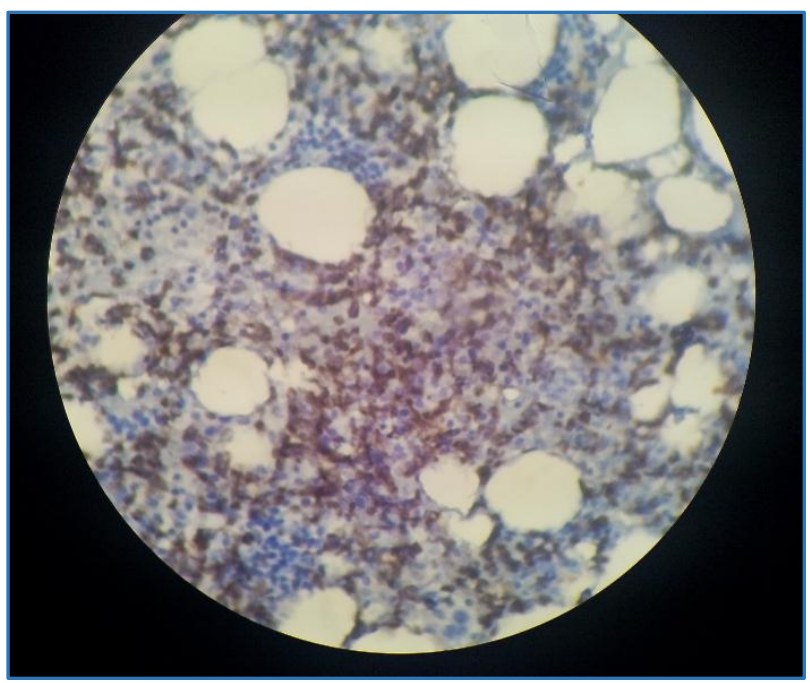

Figure 3. Bone Marrow, Cells showing Myeloperoxidase Positivity

Case 2

A 56-year-old lady with pneumonia, without any organomegaly. Her total count was 22000 per cu.mm, predominant were mature neutrophils and stab forms (Figure 4). Repeated smears showed massive increase in count, reaching up to 50000 and then 90000 per cu. mm (Figure 5). Bone marrow showed myeloid proliferation, neutrophils predominating (fig 6). Cytogenetic study revealed BCR-ABL fusion gene. 


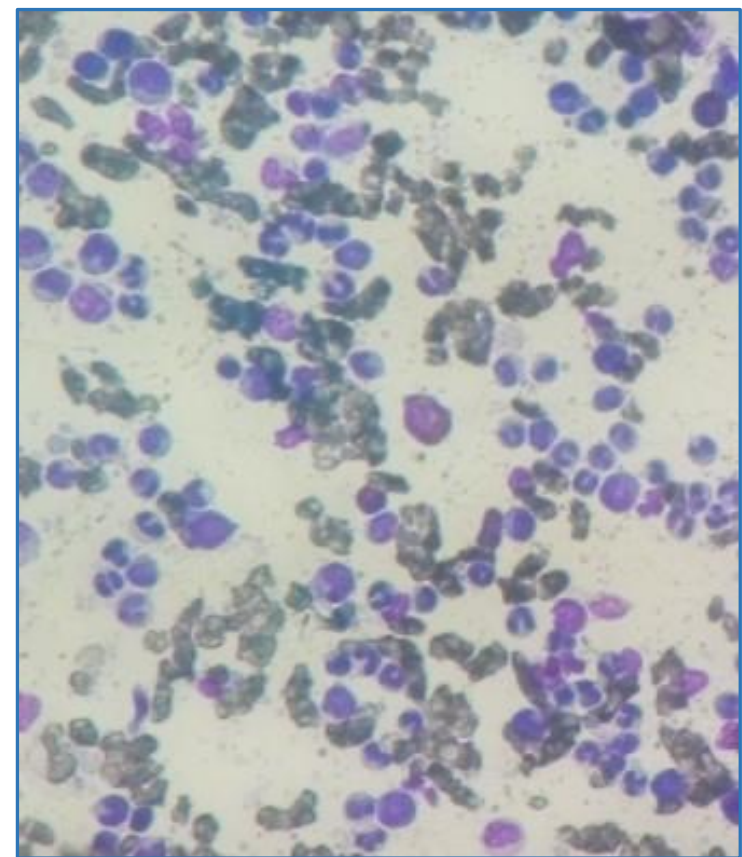

Figure 4. Smear showing Leucocytosis

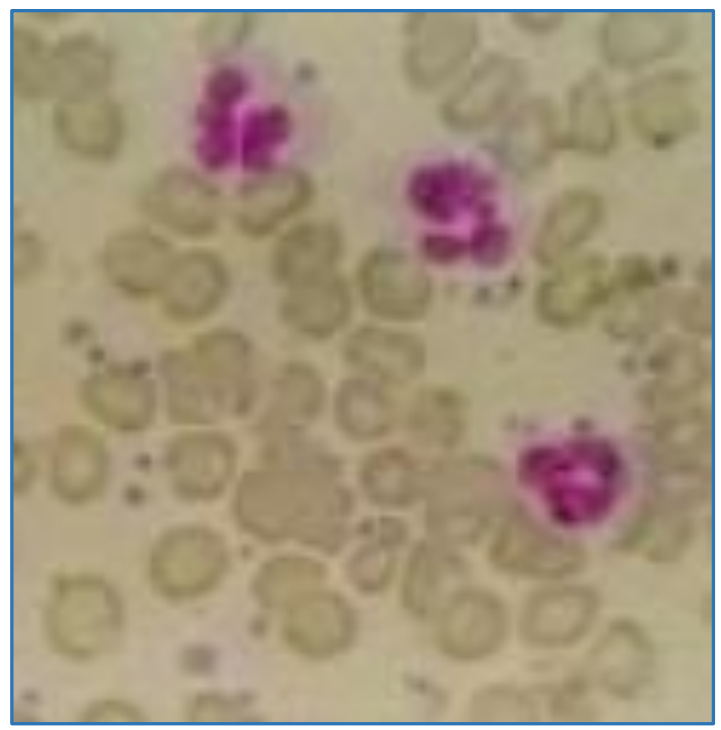

Figure 5. Repeat Smears showing Marked Leucocytosis, Predominantly Mature Neutrophils

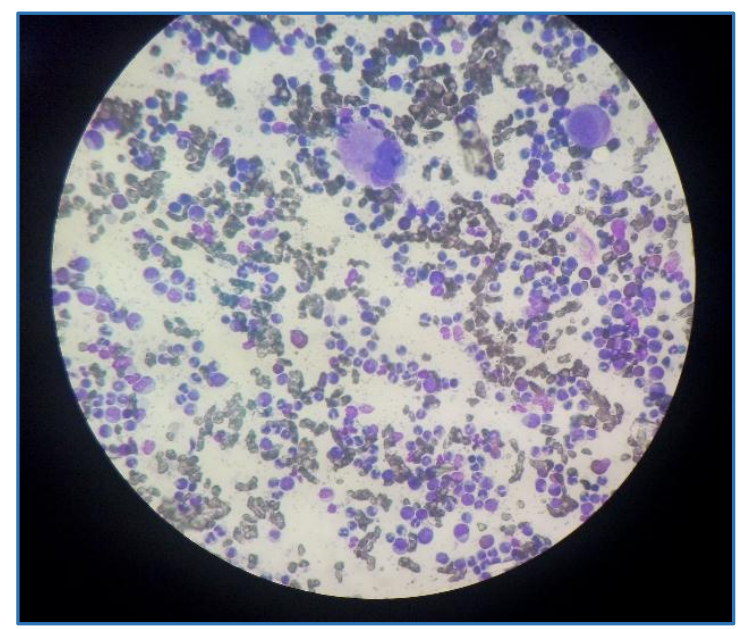

Figure 6. Bone Marrow showing Myeloproliferation. Predominantly Mature Neutrophils

\section{DIFFERENTIAL DIAGNOSIS}

\section{Case 1}

At the time of presentation, the man had severe reduction in granulocyte series. As there was no organomegaly and no cellular atypia, and since he was on antibiotics for the ulcer, the diagnosis offered was drug-induced agranulocytosis.

\section{Case 2}

The lady was having moderate leucocytosis with neutrophils constituting more than $80 \%$. Since she was having pneumonia, leucocytosis was considered reactive. As the count increased to 50000 per cu.mm, a diagnosis of leukaemoid reaction was given.

\section{PATHOLOGICAL DISCUSSION}

\section{Case 1}

After offering the diagnosis of drug-induced leucopenia, followup was advised because of mild thrombocytopenia associated. The followup smear, along with imprint from the ulcer showed atypical cells. Bone marrow aspiration was done, revealing clusters of cells, with high nucleocytoplasmic ratio, fine chromatin and two to three nucleoli. Same type of cells were seen in the smear from perianal ulcer, nuclear morphology being obscured partly by necrotic debris. Bone marrow showed sheets of atypical cells. Myeloperoxidase staining showed positivity in the atypical cells. The diagnosis of acute myeloid leukaemia with maturation was offered.

\section{Case 2}

As leucocytosis is a normal response to infection, the initial count of 22000 per cu.mm was not considered serious. When the count went up to 50000 per cu.mm, diagnosis was given as leukaemoid reaction. Absence of splenomegaly also supported the diagnosis. But the count increased up to 90000 per cu.mm, prompting a diagnosis of myeloproliferative neoplasm. Bone marrow aspiration was done for staining and cytogenetic study. Since more than $80 \%$ of white cells in blood and marrow were mature neutrophils, the diagnosis of chronic neutrophilic leukaemia was thought of. However, the demonstration of Philadelphia chromosome is against the diagnosis as the criteria for diagnosis of chronic neutrophilic leukaemia includes the exclusion of Philadelphia chromosome.

\section{DISCUSSION OF MANAGEMENT}

Leukaemias presenting with unusual symptoms were reported. In a study conducted in Nigeria, five cases of acute leukaemia were included which presented as arthritis, arthralgia and raised ESR. ${ }^{1}$ One case of acute monocytic leukaemia presented as granulocytic sarcoma. ${ }^{2}$ Other unusual presentations include pyoderma gangrenosum, DIC, and Sweet's syndrome. ${ }^{3}$ In all these cases, correct diagnosis was made with the help of repeated smears, bone marrow and chromosomal study. The cases mentioned here also can be included under the category. First case, acute myeloid leukaemia, showed cutaneous infiltration. Although it is more common in monocytic leukaemias, extramedullary infiltration is reported in AML-M2, especially those with translocation $t$ $(8 ; 21){ }^{4}$

Second case was confusing because of mild elevation in count and mature neutrophils constituting more than $80 \%$. Moreover, splenomegaly was absent. However, it is reported that about $10 \%$ cases present without splenomegaly. ${ }^{5}$ 


\section{FINAL DIAGNOSIS}

\section{Case 1}

Presence of multiple nucleoli have suggested the diagnosis of acute myeloid leukaemia, further typing could not be done. However, more than $10 \%$ cells took myeloperoxidase stain. Hence, it was reported as AML with maturation (AML-M1).

\section{Case 2}

With the bone marrow picture, a myeloproliferative neoplasm was confirmed. Possibility of chronic neutrophilic leukaemia was thought of, but the presence of the BCR-ABL fusion gene confirmed the diagnosis of Chronic Myeloid leukaemia.

\section{Conclusion}

Leukaemias are diseases which can be fatal, if prompt treatment is not given. Hence, the importance of an accurate diagnosis cannot be overemphasised. All cases with abnormal peripheral blood picture must be followed up with repeat peripheral smears and a bone marrow study.

\section{REFERENCES}

[1] Vega RA, Monson DK, Ackerman ES. Unusual presentations of leukemias. Journal of pediatric hematology 1998;20(4):407.

[2] Unusual presentation of chronic myelogenous leukemia. A review of isolated central nervous system relapse. National comprehensive cancer. Network www.dx.doi.org 2017.

[3] Tummala M. Unusual leukemia presentation. Journal of clinical oncology. www.ascopubs.org 2017.

[4] Bakst R. How i treat extramedullary acute myeloid leukaemis. Blood Journal. www.bloodjournal.org 2017.

[5] Chronic myelogenous leukaemia treatment. Health professional version. National cancer institute www.cancer.gov 2017. 